\title{
Moral Development in Adolescents as A Key Indicator for The Prevention of Violent Behavior in Their Couples' Relationships
}

\author{
Isabel Cuadrado-Gordillo*, Inmaculada Fernández-Antelo, and Guadalupe Martín-Mora Parra
}

Department of Psychology, University of Extremadura, Badajoz, Spain

\section{ARTICLE INFO}

Keywords:
Dating Violence
Moral Disengagement
Diffusion of Responsibility
Predictive Factors
Secondary Education

\begin{abstract}
Dating violence is a multidimensional and cross-cultural problem that in the last decade has extended worryingly to teenage age. The consequences are so serious and lasting over time that they cause serious psychological, educational, family and social implications. Knowledge of predictive indicators and the consequences that these aggression and victimization processes cause, can offer an important guide for the design of prevention and intervention protocols that contribute to decrease the prevalence of cases, to facilitate their identification, to give an answer faster and more efficient. This study emphasizes the moral development of adolescents as a key indicator and, specifically, in the level of moral disengagement they present. The aims are: a) Analyze the level of moral disengagement of adolescents, as well as the mechanisms they use to accept and normalize violent behaviors; $b$ ) Know what mechanisms of moral disengagement predict certain forms of aggression in dating relationships. The sample consists of 2029 adolescents (55.4\% girls) with ages between 14 and 18 years $(\mathrm{M}=16.2 ; \mathrm{SD}=1.2)$. The results indicate that adolescents have a moderate level of moral disengagement $(\mathrm{M}=2,562 ; \mathrm{SD}=0.4362)$ and the most commonly used disengagement mechanisms coincide with the diffusion and displacement of responsibility for the damage caused. As the level of disengagement increases, the mechanisms that adolescents use to validate and approve aggressive behaviors committed and suffered are diversified. Finally, it is found that the use of mechanisms such as dehumanization and euphemistic language are strong predictors of certain forms of victimization.
\end{abstract}

\section{Introduction}

Violence in adolescent dating is a poorly recognized social health problem that affects millions of young people around the world every year. This phenomenon implies a series of violent and abusive behaviors directed towards the couple whose ultimate purpose is to establish and maintain control over it. One of the biggest problems generated by dating violence is the difficulty in detecting such situations, even from within the relationship itself. On many occasions, victimized adolescents are unable to describe their relationship as abusive because the behaviors suffered (control, jealousy, insults, abuse, etc.) are seen as a normal, and even desired, way of relating. The acceptance of violence by the two members of the couple increases the chances of developing an abusive relationship between them (Smith et al., 2005). Likewise, this acceptance is considered an element of risk related to the

\footnotetext{
* Corresponding Author E-Mail Address: cuadrado@unex.es 
chronification of the phenomenon throughout life, to the point that it is common to find that victimized adolescents end up becoming victimized adults (Spriggs et al., 2009).

\subsection{Dating violence and moral disengagement}

Dating violence is an important health problem among adoelscents and young adults for its implications on physical and mental health and its consequences for individual and social development. During early and middle adolescence, the romantic relationships are a normative developmental task and the quality of these relationships is a key element for adolescents' psychological adjustment and well-being (Bonache, Gonzalez-Mendez, \& Krahé, 2017). The dynamics of later relationships will depend on the experiences, interactions and attitudes that develop in these relationships. Romantics relationships during adolescence years are linked to positive consequences for teenagers when these relations are healthy. In particular, they have a positive impact in teenagers' self concept, social competence and help them to develop skills in long-term relationships (Fisher, 2016). Nevertheless, a significant proportion of teens are likely to be victimized in these early experiences, situation that can range from instant pain and suffering to long-term psychological symptoms.

From a cognitive point of view, there are factors that may be related to teenagers' perception of dating violence. Specifically, the morality that these people have, and the mechanisms of moral disconnection they employ could affect this perception.

Research studies directed at analysing the explanatory causes of aggressive processes (Luduc et al., 2018; Simao et al., 2018), have, among other variables, emphasized the moral ones. For decades, it has been known that moral disengagement is strongly related to bullying, and can even be a predictor of it (Ortega-Ruiz et al., 2002; Gasser and Keller, 2009; Wang et al., 2017). The term moral disengagement was coined by Bandura, Barbaranelli, Caprara \& Pastorelli (1996) to refer to the process or processes used to legitimize behaviour that goes against the beliefs, values, and norms of the victims. Moral disengagement consists of a series of cognitive defence mechanisms that deactivate moral censorship and self-regulation with the aim of protecting self-esteem and self-concept. There are 8 defence mechanisms used in the process of moral disengagement:

- Moral justification, used to justify a questionable action as its having been carried out with appropriate motives.

- Euphemistic labeling, consisting in using indirect or ambiguous language to verbally minimize the severity of the objectionable actions carried out.

- Advantageous comparison, where the morally questionable action is compared with other worse actions performed before by other people.

- Displacement of responsibility, transferring the responsibility for the action carried out onto other people who have the necessary authority to order such actions, thereby legitimizing the act.

- Diffusion of responsibility, used to share the burden of the action over a group, and thus minimize the guilt that a single person would feel.

- Distortion of the consequences, consisting in diminishing the harm caused.

- Blaming the victim, in order to justify the action performed as a reaction to a previous reprehensible action by the victim.

- Dehumanization, reducing the human condition of the victim, and therefore their rights, thus making the behaviour carried out to not be so serious.

Studies focused on identifying and analysing specific moral disengagement mechanisms warn that aggressors accuse the victims of being mainly responsible for the situation they have lived through (Boulton \& Underwood, 1992). In this sense, Camodeca and Gossens (2005) indicate that aggressors claim to feel anger when they commit an aggressive act, and that this anger is greater the more hostility they previously attribute to the victims' intentions. These results were confirmed and extended by Hymel et al. (2005), who observed that the 
mechanisms most commonly used by teenagers of ages from 12 to 16 are cognitive restructuring and blaming the victim.

The aggresors' behavior has been linked to the mechanism which allow them to release the tension introduced by the contradiction between their morality and their conduct (Hymel \& Bonano, 2014; Allinson \& Bussey, 2017).

These mechanisms deactivate the censorship and self-regulation introduced by the morality in order to protect aspects such as self-steem or self-concept. These aspects have been grouped into four different loci that allow people to control their behavioral patterns. Specifically, the locus of the behavior, the agent of the action, the outcomes which emerge from the behavior, and the recipient of the actions (Bandura et al., 1996). Aggressors use these mechanisms to legitimize the violence they perpetrate that, ultimately, they can considerate as standard after applying all the process.

Little work has analyzed these moral imbalances in the role of the victim. Futhermore, little studies have considered the possibility of a link between moral disengagement and the perpetuation of the victim's role (Hood \& Duffy, 2018; Thornberg, et al., 2018). In contrast, those which have analyzed the victims' perspective tend to report a variety of conclusions, while the studies focused in aggresors are usually coincident.

Moral disengagement in victims is considered as a way to separate their inaction to scape from the situation, even justifying and minimizing the behavior of the aggressors, so that they do not actually need to face the situation or ask for help. For that purpose, victims might disengage their morality themselves (Allison \& Bussey, 2017; Luo \& Bussey, 2019). Likewise, Perren et al. (2012) indicated that victims look for moral justification of their behaviour through other victims. In this way, they usually empathise with these other victims as a way to maintain their own self-steem, and avoid the suffering.

Some studies have even found that witnesses tend to blame victims in the same way as aggressors do (DeSmetet al., 2012), denying that they themselves have any responsibility to intervene (Van Cleemput et al., 2014), and arguing either that mediation in these situations is a task that should be carried out by friends of the victim (DeSmetet al., 2012) or that the actions perpetrated are unimportant (Huang \& Chou, 2010). Recent research suggests that perhaps the key is related to collective moral disengagement which would have a mediating effect on individual morality, increasing or reducing the likelihood that witnesses will intervene.

This study emphasizes the moral development of adolescents as a key indicator and, specifically, in the level of moral disengagement they present. The aims are: a) Analyze the level of moral disengagement of adolescents, as well as the mechanisms they use to accept and normalize violent behaviors; b) Know what mechanisms of moral disengagement predict certain forms of aggression in dating relationships.

\section{Method}

\subsection{Participants}

The sample consists of 2029 adolescents (55.4\% girls) with ages between 14 and 18 years $(\mathrm{M}=16.2 ; \mathrm{SD}=1.2)$. The sample selection followed an approximately proportional stratified procedure that included 21 lower and upper secondary schools in both urban and rural populations located throughout the Region of Extremadura (Spain).

\subsection{Instrument}

For the development of this research, two different questionnaires were used.

The first instrument was Dating Violence Questionnaire, CUVINO (Rodríguez et al., 2010). This instrument was developed to assess the victimization of adolescents and youth in their dating relationships. This questionnaire consists of 61 items, grouped into three thematic 
blocks. The first of them explores the incidence of violence. It is composed of 42 behavioral items (i.e., molecular indicators) describing situations of abuse that may occur in dating relationships. It is responded on a Likert scale from 0 to 4 according to the frequency with which each item has been experienced $(0=$ never $-4=$ almost always). Total values range between 0 and 168 points; a score of 0 means no abuse by participants' boyfriend or girlfriend and scores ranging from 1 to 168 indicate the presence and the seriousness of victimization. The 42 items are clustered into eight factors that represent eight forms of abuse in dating relationships: Detachment, Humiliation, Sexual Abuse, Coercion, Physical Abuse, Gender-based Violence, Emotional Punishment and Instrumental Violence.

The second group focuses on the self-perception that adolescents have as victims of abuse; and, the third one deepens the relationship of abuse related to other aspects such as the duration of the relationship, the number of attempts to break, etc.

The second instrument was the questionnaire published by Bandura et al. (1996). This reveals the moral disengagement mechanisms that the participants apply to themselves. They are grouped into eight categories: moral justification, euphemistic language, advantageous comparison, displacement of responsibility, diffusion of responsibility, distortion of consequences, attribution of blame, and dehumanization. The presence of one or a combination of these categories provides information about the processes of moral control and the selective location of moral disengagement as a function of the focus of the behaviour, the agent of the action, the outcomes that flow from the behaviour, and the recipient of the actions.

\subsection{Procedure}

Before starting the distribution of the questionnaires to the adolescents, the research objectives and the procedure, intruments and techniques were aproved by the Bioethics and Biosafety Commitee of University of Extremadura (Spain). After that, the permision from the parents was required due to the circumstance from the participants' status as minors. Also, the permision from the Regional Education Administration was required (from both the school inspectors and the school's headteachers). In this way, it was sent a letter to the parents in which it was described the nature of the investigation, the mechanism used, guaranteeing the anonymity and the confidentiality of their children's answers. The letter was sent with an authorization of parental consent which they should sent back to shools in case they agreed with the process of the investigation. Regarding the Education Administration, the approval was obtained in two phases. First, it was sent to the Inspection Service of the Regional Government a report with the objectives, methods, and ethical principals the investigation had. After getting the aproval of this report, the access to the Region's schools was consent. Secondly, it was required the acceptance of the schools' directive teams so the researchers could access the classrooms during school hours and distribute the questionnaires.

\subsection{Data analysis}

For the identification of the victims and the forms of abuse they suffer, descriptive analyzes have been used. The exploration of the relationship between the modalities and the frequency of abuse suffered by victims and the level of moral disengagement requires a correlation analysis. Finally, the prediction analysis will require a regression analysis.

\section{Results}

The results reveal that the number of victims varies depending on the frequency of aggression suffered. When the aggression is on the 'sometimes' scale in any of the modalities analyzed, the number of victims is 1447 (811 girls, 363 boys). In relation to the age ranges, from 14 to 16 years, 708 victims are registered, from 17-18 years 583 victims are calculated and from 
19-20 years 157 victims are obtained. However, despite the fact that 1447 adolescents admit that they feel they are victims of one or more of the modalities of aggression analyzed, only 437 of them declare or perceive themselves as people mistreated by their partners, trapped in their relationship or fearful in their relationships as a couple. This data reflects that the interpretation made by victims of abuse is far from the conceptually accepted by researchers and that used at the judicial level. These results show that there are latent factors that are exerting an influence so as not to classify the repeated aggressions they suffer as situations of abuse.

The number of victims decreases significantly when considering the scale 'very often'. In this way, people who have suffered some or several forms of aggression 'very often' are considered abused (Table 1). In this case, the number of victims drops to 390.

On the other hand, the results show that the victims suffer mostly from more than one form of abuse (Table 1).

Table 1.

Prevalence of victims depending on the modality of abuse and the frequency suffered

\begin{tabular}{lccccc}
\hline Modality of abuse & \multicolumn{5}{c}{ Frequency scale } \\
\cline { 2 - 6 } & Never & Sometimes & Very often & Habitually & Always \\
\hline Detachment & 1326 & 978 & 208 & 43 & 7 \\
Humiliation & 1816 & 667 & 72 & 10 & 0 \\
Sexual & 2001 & 490 & 53 & 14 & 6 \\
Coercion & 1529 & 861 & 135 & 36 & 4 \\
Physical & 2262 & 270 & 25 & 6 & 3 \\
Gender violence & 1928 & 540 & 71 & 15 & 4 \\
Emotional & 1873 & 508 & 146 & 35 & 7 \\
Instrumental & 2423 & 100 & 36 & 5 & 1 \\
\hline
\end{tabular}

One of the latent factors that may be influencing the difference between victim selfperception and being abused could be the level of moral disengagement. The results show a relationship between victimization and moral disengagement (Table 2). Specifically, the results reveal that all forms of abuse correlate with the variable moral disengagement. Therefore, as the frequency of abuse suffered increases, the level of moral disengagement also increases.

Table 2.

Correlations between victims of forms of abuse and levels of moral disengagement

\begin{tabular}{|c|c|c|c|c|c|c|c|c|c|}
\hline & 1 & 2 & 3 & 4 & 5 & 6 & 7 & 8 & 9 \\
\hline 1. Detachment & - & & & & & & & & \\
\hline 2. Humiliation & $.678 * *$ & - & & & & & & & \\
\hline 3. Sexual & $.530 * *$ & $.565 * *$ & - & & & & & & \\
\hline 4. Coercion & $.695^{* *}$ & $.682 * *$ & $.522 * *$ & - & & & & & \\
\hline 5. Physical & $.442 * *$ & $.585^{* *}$ & $.518 * *$ & $.466^{* *}$ & - & & & & \\
\hline 6. Gender violence & $.592 * *$ & $.677 * *$ & $.599 * *$ & $.547 * *$ & $.532 * *$ & - & & & \\
\hline 7. Emotional & $.610 * *$ & $.616 * *$ & $.497 * *$ & $.647 * *$ & $.459 * *$ & $.503 * *$ & - & & \\
\hline 8. Instrumental & $.292 * *$ & $.381 * *$ & $.424 * *$ & $.317 * *$ & $.583 * *$ & $.370 * *$ & $.300 * *$ & - & \\
\hline 9. Moral disengagement & $.067 * *$ & $.071 * *$ & $.112 * *$ & $.102 * *$ & $.073 * *$ & $.062 * *$ & $.096 * *$ & $.091 * *$ & - \\
\hline
\end{tabular}

Note: ** Correlation is significant at the level of 0.01

Finally, it is analyzed whether the use of certain moral disengagement mechanisms predicts the victimization of specific forms of dating violence. For this, the disengagement mechanisms have been grouped into four blocks. The first of them, behavior locus, contains the mechanisms of moral justification, euphemistic language and advantageous comparison. 
The second, outcome locus, represents the mechanism of distortion of consequences. The third, agency locus, includes the mechanisms for diffusion and displacement of responsibility. And the fourth, locus of the recipients, refers to the mechanisms of dehumanization and attribution of blame.

The results indicate that high levels of behavior locus predict victimization of abuses related to detachment $(\beta=.39, t=10.53, \mathrm{p}<.01)$, humillation $(\beta=.32, t=10.04, \mathrm{p}<.01)$ and emotional punishment $(\beta=.26, t=9.11, \mathrm{p}<.05)$. Likewise, the detection of high levels of outcome locus can be considered predictors of victimization of sexual abuse $(\beta=.28, t=9.54, \mathrm{p}<.05)$, coercion $(\beta=.33, t=10.21, \mathrm{p}<.01)$ and physical abuse $(\beta=.21, t=7.94, \mathrm{p}<.05)$. Finally, the results show a predictive relationship between agency locus and gender-based violence $(\beta=$ $.36, t=10.32, \mathrm{p}<.01)$.

\section{Discussion}

Results show that a considerable majority of youth in our study had experienced technical abuse, since they presented evidence of having suffered abuse in their dating relationship even when they perceived themselves as not being abused. The predominant forms of abuse in the different combinations analyzed were detachment and coercion, followed by humiliation, gender based violence and emotional punishment. Physical abuse and instrumental violence had the lowest frequency of victimization. Studies on this topic have shown that psychological abuse occurs before physical abuse and even predicts it (Loinaz, et al., 2012). In our study, a considerable majority of participants reported having experienced situations of abuse, particularly psychological abuse. The most disturbing finding is that they had difficulties recognizing such behaviors as abusive. Unless the situation changes, such youth have few chances of reducing the risks of abuse in future situations and avoid future victimization (Anderson \& Kobek-Pezzarossi, 2011).

Teenagers are immature, so that, it seems that, instead of confronting the abusive situation they are expiriencing, they activate the moral disengagement mechanism which prevent them to feel the personal and social consequences of the attacks perpetrated by the aggresors (fear of exclusion and reprisals, ridicule, powerlessness, etc.). More ominously, the importance friends and peers have during this period of time may contribute to the situation making them self justify the intentionality and severity of violent behaviour perpetrated by the aggresors. Victims have developed their own expertise to analyse and interpret the situation so it does not cause irreparable damages. This concept involves a way of interpretating abuses as harmless conducts that can be seen as normal behaviour. All these facts produce the inaction of the support networks (parents, teachers, and even friends), as they have no information concerning the suffering of the victims. As a consquence, victimized teenagers are in a place where is difficult to scape, causing more defencelesness and, ultimately, turning them into polyvictims more easily. Moreover, since the suffering cannot be stopped due to the absence of clearer strategies to deal with the vulnerable situation of the victims, the impact for the adolescent's mental health is magnified, becoming a massive issue that must be perceived as a public health problem.

Individuals' inability to recognize and label a situation as abuse or violence is also explained by the "normalization" of abusive behaviors, which sometimes even leads them to be expected as signs of love (Vázquez \& Castro, 2008). In turn, this may increase individuals' need to justify the occurrence of abusive behaviors in a romantic relationship (Harned, 2005). Likewise, the findings from this study are consistent with an increasing body of research showing that moral disengagement proneness is associated with aggression. Specifically, results show the mediating power exerted by moral disengagement in the relationship between the perception of dating violence and victimization. Specifically, one can conclude that the type of perception that victims have can facilitate the activation of certain 
mechanisms of moral disengagement. According to the social cognitive theory of Bandura (2002), selective recourse to these mechanisms allows victims to reduce the tension experienced when others do not respect their moral standards and they either feel unable to put a stop to the situation or do not dare to because they fear feeling excluded or making matters worse. In this way, the victims try to play down, camouflage, or distort the intentions behind the abuses they suffer, or the motivations that led the aggressors to disseminate these abuses.

In particular, the results of this study reveal a series of indicators that facilitate the orientation of prevention and intervention programs for violence in general, and for violence in the couple in particular. These indicators show the relationship between forms of victimization and activation of certain mechanisms of moral disengagement. The aggressions related to the emotional sphere are linked to the use of mechanisms oriented to the justification of aggressive behavior. This justification can be carried out through arguments that seek as a pretext exceptional circumstances or situations that have not occurred, through the use of euphemistic terms that do not show the cruelty of aggression, or through comparisons with more serious situations to show that one's own is less and therefore bearable.

On the other hand, aggressions related to physical aspects, among which sexual abuse could also be considered, are associated with mechanisms of moral disengagement that try to distort the consequences suffered, to diminish them. This way of acting aims to protect their selfesteem and seek an impossible explanation for events that they fail to understand and that are not consistent with their moral standards (Bussey et al., 2015).

\section{Conclusion}

Over the years, moral disengagement has been bonded with some of the causes that usually motivate aggressors to perpetrate abusive behaviour toward their peers. Recently, the study of moral disengagement has been expanded to other roles such as witnesses and defenders of the victims to create better prevention programs both for children and teenagers. Nevertheless, there are not many studies focus on the possible relation between moral disengagement and victimization which has also been relegated and considered as a secondary link impeding the comparisons between studies and the introduction of supplementary variables that could have a very important role in this phenomenon. One of the most notable contributions of the present work is the analysis of the processes of moral disengagement in victims, and the influence these processes have on the durability of their role as victims.

\section{Acknowledgment}

This paper is an output of the research project IB16011 financed by the Government of Extremadura and funds Feder.

\section{References}

Allison, K. R., \& Bussey, K. (2017). Individual and collective moral influences on intervention in cyberbullying, Computer in Human Behavior, 74, 7-15.

Anderson, M. L., \& Kobek-Pezzarossi, C. M. (2011). Is it abuse? Deaf female undergraduates' labeling of partner violence, Journal of Deaf Studies and Deaf Education, 17, 273-286.

Bandura, A., Barbaranelli, C., Caprara, G. V., \& Pastorelli, C. (1996). Mechanisms of moral disengagement in the exercise of moral agency, Journal of Personality and Social Psychology, 71(2), 364-374.

Boulton, M. J., \& Underwood, K. (1992). Bully/victim problems among middle school children, British Journal of Educational Psychology, 62, 73-83. 
Bussey, K., Fitzpatrick, S., \& Raman, A. (2015). The role of moral disengagement and selfefficacy in cyberbullying, Journal of School Violence, 14(1), 30-46.

Camodeca, M., \& Gossens F. (2005). Aggression, social cognitions, anger and sadness in bullies and victims, Journal of Child Psychology and Psychiatry, 46(2), 186-197.

DeSmet, A., Bastiaensens, S., Van Cleemput, K., Poels, K., Vandebosch, H., Cardon, G., et al. (2016). Deciding whether to look after them, to like it, or leave it: A multidimensional analysis of predictors of positive and negative bystander behavior in cyberbullying among adolescents, Computer in Human Behavior, 57, 398-415.

Gasser, L., \& Keller, M. (2009). Are the competent the morally good? Perspective taking and moral motivation of children involved in bullying, Social Development, 18(4), 798-816.

Harned, M. S. (2005). Understanding women's labeling of unwanted sexual experiences with dating partners: A qualitative analysis, Violence against women, 11(3), 374-413.

Hood, M., \& Duffy, A. L. (2018). Understanding the relationship between cybervictimization and cyber-bullying on Social Network Sites: The role of moderating factors, Personality and Individual Differences, 133, 103-108.

Huang, Y., \& Chou, C. (2010). An analysis of multiple factors of cyberbullying among junior high school students in Taiwan, Computers in Human Behavior, 26, 1581-1590.

Hymel, S., \& Bonano, R. A. (2014). Moral disengagement processes in bullying, Theory into Practice, 53(4), 278-285.

Hymel, S., Rocke-Henderson, N., \& Bonanno, R. (2005). Moral disengagement: a framework for understanding bullying among adolescents, Journal of the Social Sciences, 8, 1-11.

Loinaz, I. Ortiz-Tallo, M., \& Ferragut, M. (2012). MCMI-III Grossman personality facets among partner-violent men in prision, International Journal of Clinical and Health Psychology, 12(3), 389-404.

Luduc, K., Conway, L., Gomez, C., \& Talwar, V. (2018). The influence of participant role, gender, and age in elementary and high-school children's moral justifications of cyberbullying behaviors, Computer in Human Behavior, 83, 215-220.

Luo, A., \& Bussey, K. (2019). The selectivity of moral disengagement in defenders of cyberbullying: Contextual moral disengagement, Computer in Human Behavior, 93, 318325.

Ortega-Ruiz, R., Sánchez, V., \& Menesini, R. (2002). Bullying and moral disengagement: A cross-national comparison, Psicothema, 14, 37-49.

Perren, S., Gutzwiller-Helfenfinger, E., Malti, T., \& Hymel, S. (2012). Moral reasoning and emotion attributions of adolescent bullies, victims, and bully-victims, British Journal of Developmental Psycholology, 30(4), 511-530.

Rodríguez-Franco, L., López-Cepero, J., Rodríguez, F. J., Bringas, C., Antuña, M.A., \& Estrada, C. (2010). Validación del cuestionario de violencia entre novios (CUVINO) en jóvenes hispanohablantes: Análisis de resultados en España, México y Argentina, Anuario de Psicología Clínica y de la Salud, 6, 45-52.

Simao, A. M., Ferreira, P., Francisco, S. M., Paulino, P., \& Souza, S. B. (2018). Cyberbullying: Shaping the use of verbal aggression through normative moral beliefs and self-efficacy, New Media and Society, 20(12), 4787-4806. 
Smith, A., Winokur, K., \& Palenski, J. (2005). What is dating violence?, Journal of Ethnicity in Criminal Justice, 3(1-2), 1-20.

Spriggs, A. L., Halpern, C. T., \& Martin, S. L. (2009). Continuity of adolescent and early adult partner violence victimisation: association with witnessing violent crime in adolescence, Journal of Epidemiology \& Community Health, 63(9), 741-748.

Thornberg, R., Waenstroem, L., Pozzoli, T., \& Gini, G. (2018). Victim prevalence in bullying and its association with teacher-student and student-student relationships and class moral disengagement: A class-level path analysis, Research Papers in Education, 33(3), 320-355.

Van Cleemput, K., Vandebosch, H., \& Pabian, S. (2014). Personal characteristics and contextual factors that determine "helping," "joining in," and "doing nothing" when witnessing cyberbullying, Aggressive Behavior, 40(5), 383-396.

Vázquez, G. V., \& Castro, R. (2008). ¿Mi novio sería capaz de matarme? Violencia en el noviazgo entre adolescentes de la Universidad Autónoma Chapingo, Mexico, Revista Latinoamericana de Ciencias Sociales, Niñez y Juventud, 6, 709-738.

Wang, X., Yang, L., Yang, J., Wang, P., \& Lei, L. (2017). Trait anger and cyberbullying among young adults: A moderated mediation model of moral disengagement and moral identity, Computer in Human Behavior, 73, 519-526. 